\title{
Invisible data quality issues in a CRM implementation
}

Received (in revised form): 20th April, 2005

\begin{abstract}
Andrea Reid
is a PhD candidate at the School of Management \& Economics at Queen's University Belfast. Her research interests are relationship marketing, customer relationship management, single view of the customer databases, the use of IT in marketing, data quality and marketers trust of data held within databases. She has previous experience working as a software engineer developing a single view of customer databases.

\section{Miriam Catterall}

is a senior lecturer in management at the Queen's University Belfast, where she is responsible for marketing and research methods programmes. She has considerable business experience in the market research industry and in management consulting. Her research interests lie in consumer research, feminist issues in marketing and in qualitative market research, particularly in focus group theory, methodology and practice.
\end{abstract}

Abstract Poor data quality can have a severe impact on the overall effectiveness of an organisation. Data quality problems, which are prevalent in many customer relationship management $(\mathrm{CRM})$ implementations, receive limited attention in the literature. Few organisations account for these problems when planning a CRM project. This is often because data quality problems do not become apparent until the project is underway, when the time and costs required to address them can be substantial and beyond the project budget limits. This paper uses illustrative case study examples of problems encountered when implementing CRM and highlights the need for further research in this area.

\section{INTRODUCTION}

The literature is now full of strategies for successful customer relationship marketing (CRM) implementations and case examples highlighting success factors. ${ }^{1-3}$ Data quality problems, which are prevalent in many CRM implementations, receive limited attention in the literature. Few organisations account for these problems when planning a CRM project. This is often because data quality problems do

Andrea Reid

School of Management \& Economics, Queens' University Belfast, 107 Botanic Avenue, Belfast, BT7 1JP, Northern Ireland, UK.

Tel: $+44(0) 2890273306$ (Ext 23);

e-mail: a.m.reid@qub.ac.uk not become apparent until the project is underway, when the time and costs required to address them can be substantial and beyond the project budget limits. ${ }^{4,5}$ If dealt with at the strategy formulation stage, however, improved data quality can improve operational costs, customer satisfaction, effective decision-making ${ }^{6}$ and, importantly, employee confidence in CRM.

This paper focuses on data quality problems that appeared in a CRM implementation in a large European telecommunications company. It illustrates how data quality issues were invisible until the CRM implementation was well underway and how failure to include these extra costs in the budget and set a timetable to address potential problems jeopardised the success of the project, particularly amongst user groups. The paper begins with a brief review of the literature on data quality. This is followed by an outline of the case study company and the data collection methods used. Three of the data quality problems that emerged in the course of CRM implementation and their impact on the 
project are discussed in the findings section. This is then followed by a proposed strategy to improve data quality and a conclusion which considers factors that could address invisible data quality problems.

\section{THE IMPORTANCE OF IMPROVED DATA QUALITY}

Data and information are strategic enterprise resources. Good quality information enables business effectiveness and competitive advantage. It is an inherent and integral part of business management. ${ }^{7,8}$ High quality, well-integrated customer data are the cornerstone of a successful CRM project. It is vital when eliminating excess operational costs caused by redundant data and when trying to improve revenue through better customer targeting and retention. ${ }^{9,10}$ Good quality data enable CRM strategies to be more effective and efficient but many organisations are failing to invest in improving the quality of their data. ${ }^{11}$ With the volume of data that is stored in data warehouses/databases worldwide, it is becoming a huge challenge to manage this data to provide quality information.

English states that information quality today is getting worse, and that in some companies it is so bad that it is an enterprise threat. ${ }^{12}$ In many cases, CRM's potential to improve customer service and increase revenue has been prevented by inconsistent data sets that prevent the organisation having a clear unified profile of each customer. Gartner has reported this problem to be widespread and has found that more than 75 per cent of organisations engaged in CRM initiatives cannot combine a comprehensive view of a customer with actionable, personalised advice to customer sales and service agents. ${ }^{13}$ It is estimated that poor data quality costs businesses $\$ 611$ billion per year in the United States alone and only 33 per cent of businesses feel confident in the quality of their organisation's data. ${ }^{14}$ Similarly, a recent study conducted by the Data Warehousing Institute suggests that poor quality data can result in losses of 10-25 per cent of organisations' revenues. ${ }^{15}$

Data quality indicates how well enterprise data matches up with the real world at any given time. ${ }^{16}$ There are many sources of 'dirty data'; Cutter Consortium $^{17}$ identified the following sources:

1 Poor data entry, which includes misspellings, typographical errors and transpositions, and variations in spelling or naming.

2 Data missing from database fields.

3 Lack of company-wide or industry-wide data coding standards.

4 Multiple databases scattered throughout different departments or organisations, with the data in each structured according to the rules of that particular database.

5 Older systems that contain poorly documented or obsolete data.

One solution to the problem of 'dirty data' or poor quality data is data cleansing or scrubbing. The goal in a data cleansing or scrubbing initiative is to bring consistency to various data sets that may have been created with different, incompatible business rules. Data cleansing can help in the challenge of obtaining error-free and consistent data and is an essential function in any CRM system. It is only a starting point to improving data quality, however. ${ }^{18}$ As an approach, cleansing has been likened to taking a shower at the beginning of the month and saying 'Now I'm clean!' Data quality is a constant commitment and it is necessary to put some kind of metrics in place to continuously measure the 
quality of the data. This is because CRM is prone to more corrupt data than other enterprise applications. ${ }^{19}$

Many organisations are aiming to achieve customer data integration, this requires the integration of front and back office systems and is the 'powerhouse' for CRM. This database pulls all enterprise data together into one database in real time so that all data held on each customer, including contact history, is available to all departments when and where they want it, giving a full 360 degree view of each customer. ${ }^{20}$ Integrating customer data sets is extremely challenging, as CRM has such a broad scope. For example, in a typical bank there could be 50 to 150 different systems which contain customer data. To gain a single view of each customer and their value and needs, all the data need to be combined. This requires pulling together different data stores with data from various sources stored in different databases. These data stores use a range of programming languages and data formats. Some of the data may be of poor quality and might not have been used for some considerable time; hence integrating this data is an enormous task. $^{21}$

Data warehousing has exposed terrible data quality problems that only become apparent when a company tries to integrate disparate data for CRM. ${ }^{22}$ Inconsistencies between the ways in which information is held by different units may not matter until this data is made enterprise-wide and used to analyse customers. Data that were sufficient for operational systems has often proved insufficient for CRM databases or data warehouses. ${ }^{23}$

English uses an example of an insurance company that was shocked when it downloaded data from its claims processing centre and found that 80 per cent of claims apparently involved broken legs. ${ }^{24}$ When the company investigated this it found that the code used to indicate a broken leg was the default code in the system used to process claims. The claims processors were paid according to how fast they worked and used a default code to speed up the processing of each claim. It did not matter that the wrong code was used while the claim was being processed, it only caused problems later when the company tried to use the data to analyse the patterns of diagnoses for which it was paying claims.

Furthermore, traditional back office systems require a limited number of people to process data, whereas in CRM, almost everyone in an organisation interacts with part of the application. This results in a higher probability of poor data. In a similar vein, web-based data entry can add to data quality problems. A competent data entry clerk has an average error rate of 2-4 per cent. By contrast, the error rate on the web is $10-15$ per cent, since it is members of the public that are entering the data. ${ }^{25}$

For these reasons, traditional approaches to improving data quality are insufficiently robust. Traditional data quality tools are batch-oriented and single-shot endeavours. With CRM systems there is a need for transactional, real-time solutions. One solution to this problem is a continuous data quality management tool which provides a real-time, up-to-date scorecard to measure data quality within an organisation. This will check the data quality in real-time, which in turn means 'data fires' can be detected when they are just starting and before any real damage has occurred; in other words a type of 'smoke detector' which proves less expensive to put right. ${ }^{26}$ Of course, due to the large expense involved not all organisations involved in these data 
quality initiatives are in favour of investing in this type of tool. The increasing awareness of the value of good quality data has led to a growth in acquisitions of vendors of data cleansing software. The interest is mainly driven by e-business initiatives such as online commerce across the organisations' many divisions and the need to get a single accurate view of each customer. ${ }^{27}$

Most analysts agree that data quality has become a pressing issue and that it is time to reassess system design to ensure that inaccurate data does not get into systems in the first place. ${ }^{28-31}$ English states that data quality is something one designs in and not something one inspects out. ${ }^{32}$ One emerging trend involves applying data cleansing technology to defect prevention by operating at the data entry point. ${ }^{33}$ For larger organisations the answer may be to invest in one of the real-time data integration suites that are now more readily available.

Of course, organisations are rarely able to achieve 100 per cent accuracy and integrity. However, poor data quality impacts on trust and confidence in expensive CRM systems, especially among sales and marketing staff who are often in the 'front line' of trying to realise the benefits of CRM. Many marketers, especially those who expected better quality information would result from the loading of legacy data into expensive CRM systems and sales force automation systems, have been disappointed as sales leads generated from the new system are no more deliverable than the leads out of the old system. ${ }^{34,35}$ As Abbott found in her study about customer data held within databases in the UK, virtually all respondents agreed that more data helped marketers to do a better jobs, but that the data had to be good as bad data hindered campaigns and eventually lead to mistrust. ${ }^{36}$
In summary then, more attention needs to be given to making expensive CRM infrastructure actionable by improving data quality. ${ }^{37}$ Moreover, senior management need to support quality initiatives to improve their chances of success. ${ }^{38}$

\section{RESEARCH METHODOLOGY}

The overall aim of this ongoing research is to find out how one organisation has dealt with data quality as part of its CRM planning and implementation. More particularly, the research examines how the company is planning for and addressing data quality issues and the reasons why certain decisions have been made. As this research problem is a 'how and why?' problem rather than a 'what and how should?' problem, qualitative case-based research was deemed to be appropriate to allow for an in-depth view of the phenomena from the perspectives of the multiple parties involved in the CRM implementation. ${ }^{39,40}$

This case study company is a leading provider in the European telecommunications marketplace. Its key activities include the provision of fixed line switched telephony services and associated value-added services such as voice mail, call management services and so on - both in retail and wholesale markets. The company also provides high-end data products such as leased line and frame relay products and associated value-added integration services in both retail and wholesale markets. It has a strong market leadership position in its domestic market and is the key supplier of infrastructure services in the wholesale market.

Access to company staff in all the various departments involved in the CRM implementation was agreed at the most senior level within the company. 
Additionally, access to the vendor of CRM software solutions and other related services was also agreed. In the case of the company and its suppliers, access was granted on the basis of various confidentiality agreements.

At the beginning of the research, secondary data was collected in the form of business case reports, management reports and project history repositories to provide a basis for socio-historical referencing of the CRM implementation which included their strategy for data quality and to supply information about any future marketing strategies that are being developed. After analysing the secondary data, senior management and other staff within the Information Technology (IT), Marketing and CRM departments were interviewed to find out how these strategies were being implemented. These departments were selected first since they are primarily responsible for the development and execution of CRM strategies and are ultimately responsible for data quality. At each new milestone in the CRM project, staff in these departments are re-interviewed.

The following section is an overview of the major data quality problems that emerged early in the company's CRM implementation. The attempts made to address them are also discussed.

\section{OVERVIEW OF MAJOR PROBLEMS UNCOVERED}

The case study company has been involved in implementing CRM strategies since the late 1990s and is currently involved in a full overhaul of its systems. This involves implementing a new database to integrate all customer data and a new high tech speech recognition system to deal with a large selection of customer calls. As a result, the quality of the data that have been housed within separate databases across the company has become a key issue.

In 2000 , the company made a first attempt at customer data integration that involved migrating data from old legacy systems to a new central database. This was an operational database (ie a database that supports the daily running of the organisation). Data was initially migrated to the central database, periodically, data was then exported out of the central database back to the legacy systems and back again as part of the operational running of the systems. The importing and exporting of data resulted in a number of data quality problems. To illustrate, when data were exported from the new central database back into a legacy system, some of the customer address matches that had been performed by the new database were undone, a problem that had not been imagined and which was uncovered only at the software testing phase of the implementation.

Problems with the data that had been stored in the new central database, were also covered. These included poor matching of individual customer records, duplicate customer records and missing fields, all of which where only discovered when trying to integrate the data. These problems increased support and maintenance costs for the new database and, importantly, led to a lack of support for the new database amongst user groups. A business consultant on the project explained that the Marketing department took information from the central database but it did not add value to them; hence, marketing processes did not alter to take advantage of what the new data integration database might have provided. Data quality has therefore become a key issue since poor data quality could result in customer attrition and hence reduce revenue. 
A review of business processes was necessary to find out how the data would actually be created and used and this uncovered significant data quality issues that were missed during the first build of the database. Three of these will now be discussed in more depth.

\section{FINDINGS}

\section{Data input via call centre agents}

The case study company has several call centres that deal with inbound and outbound calls. Call centre agents were traditionally incentivised by the speed of answer, ie the number of calls they could answer in one working shift and the completeness of each form on screen. With this focus, call centre agents did not understand the importance of the quality of the data that they were entering.

Previously within the company, customer data were collected via the call centre but not used for data mining and customer analysis. Hence, little concern was given to the quality of the data collected, meaning that it did not really matter that default codes were input into the system so long as the call centre agent answered more calls in a working shift and each form was completed fully (though each free text field may have only had an 'a', 'b' or 'c' entered). The shift to CRM meant that the quality of the data that were entered at this contact point had to change, as the data would be needed for data mining, for analysis of the effectiveness and efficiency of various marketing campaigns and so on.

To overcome this problem, call centre agents have a measure of data quality included in any coaching sessions. The employee review process includes how staff have handled a call, whether they have used proper lookups and undertaken a proper search for an existing address before entering a new one and so on - all of which adds, in a very practical way, into their performance measurements and rewards. The financial implications for this are substantial and add to an already overstretched CRM implementation budget. It should, however, improve the quality of the data that are being collected by the call centre. Unfortunately, it does not solve the problem of the quality of the data already stored on the database or the data that are being gathered via the self-service channels.

\section{Self-service channels}

This organisation's objectives include improvement in operational efficiency and achieving an acceptable level of customer intimacy. To achieve these objectives it is attempting to encourage more customers to use self-service channels such as the web or the new speech recognition system.

The costs of actually implementing this system significantly exceed the original budget, however. In particular, a whole new set of data validation rules for internet channels had to be designed and implemented. To illustrate, if a customer uses the web to order a new product but cannot remember his/her username and password, he/she can create themselves as a new customer; without data validation rules, there would be no way to match the new account to an existing account.

Designing and implementing data validation rules on the web may seem a fairly straightforward operation but the costs involved are substantial due both to the resource commitment required from the IT department and the technology required. The company is unable to support this data validation programme this year due to lack of funding. The IT team have advised against this, but senior 
management suggest that this 'dirty data' problem can be addressed next year when money can be set aside for this purpose. This is not abnormal with CRM implementation projects; however it does imply that the senior management team are not fully committed to the idea of improving data quality.

\section{Failed customer matching process}

Data on customers were recorded in the separate legacy systems. The migration of these data to a new central integrated database uncovered significant problems. Normally in these situations this would be achieved by matching postcode data, which is employed in most consumer markets across Europe and the USA as a 'unique' customer identifier along with possibly the house number. The European domestic market in which this company operates does not have a postcode system, however. One of the principal business consultants reported, that: 'Somewhere between 30 and 40 per cent of all customer addresses are non-unique and only made unique by the person who lives there. So if a person moves and you have two addresses that are alike then you can't trace the customer. Our company have a slight advantage of having their own database which stores the location of all the cables and where they go but trying to match that up to physical addresses is pretty difficult.'

This is a common problem for all types of business within the region. For example, to operate the postal system efficiently, highly knowledgeable mail sorters and postmen are required to deliver the mail. They have to be familiar with every single street name and house number in order to be able to sort the mail correctly first time and to deliver it efficiently. This is particularly the case in rural areas. Many rural homes have no house number, and so the delivery of the mail depends on the postman knowing exactly who is living in which house. This is all the more difficult in areas where many people share the same surname. The lack of postcodes prevents customers ordering goods via the internet as this is usually a mandatory field within any order form online.

As part of the customer matching process being conducted within the company, it was discovered, that within one state in the region there can be 20-30 houses sharing the same address and the same surname. This resulted in the possibility of a one in 30 chance of matching customer data correctly, thus no match was possible. In the new database, these customers had to be stored as separate customers, therefore making it impossible for this company to know exactly how many customers it has, due to the same customer being stored several times within the database.

The matching process was further complicated by other data quality problems, such as missing fields within customer records stored in the old system and address formats being stored differently. To illustrate, within one legacy system, addresses were stored with house number and street name in one field called 'address line one', but in another, it was stored as house number in 'address line one' and street name in 'address line two'. Trying to merge this data is very difficult, as the matching software will not make a match because the two fields contain different data, even though they may refer to the same customer. This organisation therefore invokes manual intervention, where the data are sent to a data enrichment department for employees to manually match the customers by contacting them to check and update their details. The 
time taken to do this adds a huge cost to the project.

The data migration process failed to tackle the fundamental issues of data quality (conformance to standard, existence of duplicates). Consequently, the new database included all the assumptions and data quality issues from the original legacy systems from which the data were migrated. Flawed assumptions and contradictory business rules existing in the original legacy systems were also migrated into the new central database. There was an obvious lack of any type of data management strategy within this phase.

The solution to this problem would be to invest in a data cleansing tool which will reformat the data within the old system before it is migrated to the new database so that only clean data is stored there; however, within this market, special tools need to be developed to cope with the lack of a postcode in the address. This organisation has been talking to a vendor organisation that has developed such a tool, but again, this is at a huge cost and it is difficult to engender senior management support for these data quality initiatives, as the rewards are not always obvious upfront.

\section{DATA MANAGEMENT STRATEGY}

It is clear from these findings that a data management strategy or framework needs to be put in place before any CRM implementation begins. Reflecting on personal experience in the field and in conjunction with data collected from the case organisation, a socio-historical perspective was attained which provided the basis for the following strategy. This represents a possible high level strategy to aid the identification and treatment of data quality issues in data driven systems:
1 Identify the main sources of data for the organisation; eg the accounts system for customer details, the billing system for addresses and so on.

2 Undertake an initial data quality assessment of these main data sources, this will try to identify a baseline for the data quality; eg are 20 per cent of cases missing the date of birth (DOB), is there malformed address information, is there no common use of fields or do fields contain data that the company does not intend to keep.

3 Utilise this information to drive an immediate clean-up activity, this may involve performing an initial clean of the systems to include items such as postal address file (PAF). Many of these processes may need to be manual if the data quality is very poor.

4 Form an on-going programme of work to gradually improve the quality of the data; examples include adding an extra data capture step to capture DOB, implementing changes in process to accommodate better data entry or improve staff training/awareness. It may be useful to attach a data quality measure to each key item so that targets can be set and progress can be measured. This stops unrealistic targets of 100 per cent clean data and it helps to pinpoint where you are on the journey.

To facilitate this strategy, an overall 'data governor' will be required at senior management level. The data governor should be aware of the organisation's business processes and the implications of poor quality data on them. As such, he/she should be trusted and respected within the organisation to ensure that people take notice of his/her requests. The organisation should give the data governor access to data quality reports and the mechanisms to continually monitor them, so he/she can be 
empowered to make the necessary changes required to improve data quality.

A data governor should not be seen as the 'magic fix' that will solve all the problems, however, or be cast in a temporary role, as improving data quality is a continual process of business improvement. ${ }^{41,42}$

It should be noted that the position of data governor should not be used as a scapegoat for problems that may continue in this evolving process. The resulting improvement in the quality of the data should increase the effectiveness and efficiency of the organisation as a consequence of such strategies being put in place. ${ }^{43,44}$

\section{CONCLUSION AND FURTHER RESEARCH}

These examples illustrate the otherwise invisible data quality problems that can emerge when transferring data from old legacy systems to new integrated customer databases in CRM implementation. Each of the examples shows that it is not always possible to identify data quality problems and more specifically - the scope of these problems, at the system specification stage. Undoubtedly, it is a somewhat complex problem to estimate the time and budget that will be required to address these issues in advance.

It could be argued, however, that the case study company should have recognised in advance that problems would arise in matching customer data held in various legacy systems with respect to the lack of a 'unique' identifier such as a postcode. Although, the company had worked very successfully in its domestic markets without postcodes in the past, the company remains market leader in its domestic market.

Of course, even when problems are recognised at an early stage, it may still prove difficult to address them. The examples relating to data collection points illustrate the problems that companies face. The changes to call centre agents, remuneration will have an impact on the quality of data that is now being collected from customers. The organisation is encouraging customers to use self-service channels. The problems associated with data validation via the web channel need to be given a higher priority; the delaying of such a measure heightens the problem of 'dirty data' and, as a consequence, increases costs. Possibly the money spent on the implementation of the new speech recognition system should have been used to improve the quality of the data, but the company sees this new system as giving it a competitive advantage as it is the first system of its kind within the region. It is very difficult when dealing with limited budgets to decide where the money would be best spent.

As more and more organisations recognise that the data they store is a valuable asset, it is essential that a comprehensive data management strategy is put in place at the beginning of any CRM implementation. The problem needs to be addressed enterprise-wide, with an enterprise-wide view of providing a solution. The high level strategy put forward in this research could be used as a foundation on which to build a complete framework to alleviate the invisible data quality issues that may emerge during CRM implementation.

An enterprise-wide solution is also required to resolve problems relating to the ownership of the central integrated customer database - the CRM 'powerhouse'. Separate legacy systems are 'owned' by the individual departments within the company that houses them. These departments are responsible for, 
and accountable for, 'their' data. As data are migrated from these legacy systems to an organisation-wide central database, issues of data ownership along with data responsibility and accountability arise. Put simply, 'who now owns the data'?

Finally, further research is needed to identify other 'invisible' data quality problems and how and if these are being addressed. Very often CRM case studies present implementation issues in a positive light. It needs to be recognised, however, that not all problems encountered are solvable, or can be solved within reasonable time and budget limits.

\section{References}

1 Crosby, L. A. (2002) 'Exploding some myths about customer relationship management', Managing Service Quality, Vol. 12, No. 5, pp. 271-277.

2 Sheth J. N. and Sisodia, R. S. (2001) 'High performance marketing', Marketing Management, Vol. 10, No. 3, pp. 18-24.

3 Winer, R. S. (2001) 'A framework for customer relationship management', California Management Review, Vol. 43, No. 4, pp. 89-108.

4 English, L. (1999a) 'Improving data warehouse and business information quality: Methods for reducing costs and increasing profits', John Wiley and Sons, New York, NY.

5 Thompson, O. (2003) 'Poor data quality means a waste of money', available at: www.technologyevaluation.com, accessed August 3rd, 2004.

6 Redman, T. C. (1998) 'The impact of poor data quality on the typical enterprise', Communications of the Association of Computing Machinery, Vol. 41, No. 2, pp. 79-82.

7 English, L. (1999b) 'Plain English on data quality: The high costs of low quality data', available at: www.identex.com, accessed 2003.

8 Ramesan, K. (2004) 'Data quality: Cost or profit?' available at: www.technologyevaluation.com, accessed August 3rd, 2004.

9 Ramesan (2004) ibid.

10 Peikin, D. (2003) 'Data quality: The foundation for effective CRM', Target Marketing, Vol. 26, No. 2, pp. $49-50$.

11 Abbott, J., Stone, M. and Buttle, F. (2001) 'Customer relationship management in practice A qualitative study', Journal of Database Marketing, Vol. 9, No. 1, pp. 24-34.

12 English (1999a) op. cit.
13 Krill, P. (2001) 'Data quality issues plague CRM', InfoWorld, Vol. 23, No. 41, p. 39.

14 Leman, G. (2002) 'Continuous data quality management: The cornerstone of zero-latency business analytics. Part 2: One solution', available at: www.technologyevaluation.com, accessed August 3rd, 2004.

15 Chettayar, K. (2002) 'Using customer information effectively', Financial Executive, Vol. 18, No. 3, p. 42 .

16 Leman (2002) op. cit.

17 Peterson, T. (2003) 'Data Scrubbing', Computerworld, Vol. 37, No. 6, p. 32.

18 Peterson (2003) ibid.

19 Leman (2002) op. cit.

20 Winer (2001) op. cit.

21 Krill (2001) op. cit.

22 Redman, T. C. (1996) 'Why care about data quality? data quality for the information age', Artech House, Norwood, MA, p. 9.

23 Faden, M. (2000) 'Data cleansing helps e-businesses run more efficiently', Information Week, Vol. 781, p. 136.

24 English (1999a) op. cit.

25 Krill (2001) op. cit.

26 Leman (2002) op. cit.

27 Faden, M. (2000) 'Clean up your data act', Internet Week, Vol. 809, p. 60.

28 Ramesan (2004) op. cit.

29 Krill (2001) op. cit.

30 Redman (1996) op. cit.

31 Peikin, D. (2003) 'Data quality: The foundation for effective CRM', Target Marketing, Vol. 26, No. 2, p. 49.

32 English (1999) op. cit.

33 Faden (2000) op. cit.

34 Peterson (2003) op. cit.

35 Foss, B. and Stone, M. (2001) 'Successful customer relationship marketing', 1st edn., Kogan Page Limited, London, UK.

36 Abbott, J. (2000) 'Data data everywhere - And not a byte of use', IBM Business Intelligence Solutions, Vol. 4, No. 3, pp. 182-192.

37 Kapochunas, A. (2002) 'ROI begins with improved data quality', Target Marketing, Vol. 25, No. 7, p. 58.

38 Foss, B., Henderson, I., Johnson, P. et al. (2002) 'Managing the quality and completeness of customer data', Journal of Database Marketing, Vol. 10, No. 2, pp. 139-158.

39 Gill, J. and Johnson, P. (1991) 'Research methods for managers', First Edition, Paul Chapman Publishing, London, UK.

40 Yin, R. A. (2003) 'Case study research design and methods', Third Edition, Sage Publications, Thousand Oaks, CA.

41 Krill (2001) op. cit.

42 Winer (2001) op. cit.

43 Redman (1998) op. cit.

44 Peikin (2003) op. cit. 